\title{
ECONOMIA POPULAR E EDUCAÇÃO: PERCURSOS DE UMA COOPERATIVA DE RECICLAGEM DE LIXO NO RIO DE JANEIRO
}

\author{
POPULAR ECONOMY AND EDUCATION: PATHS OF A WASTE RECYCLING COOPERATIVE IN RIO \\ DE JANEIRO
}

Ana Maria Marques Santos ${ }^{1}$

Neise Deluiz ${ }^{2}$

Resumo Este artigo busca analisar as práticas de uma cooperativa de reciclagem de lixo situada na Baixada Fluminense, Rio de Janeiro, enfocando a organização e as relações de trabalho; os saberes produzidos nos processos de trabalho e as redes de ação coletiva estabelecidas com a comunidade. Os dados foram obtidos através de entrevistas realizadas com os cooperados e suas lideranças e com os técnicos da ONG Autre Terre, que apoia o projeto. Os resultados da pesquisa qualitativa apontam que esta experiência de economia popular e solidária tornou-se uma alternativa de inclusão social, gerando trabalho e renda, além de saberes e valores, na perspectiva de uma educação popular crítica. Nas relações da cooperativa com a comunidade são estabelecidas redes de ação coletiva, resgatando-se o espaço público, no qual a publicização da diversidade de ideias e concepções pode viabilizar o exercício da cidadania.

Palavras-chave economia solidária; educação popular; movimentos sociais; cooperativismo.
Abstract This article analyzes the practices of a waste recycling cooperative located in Baixada Fluminense, Rio de Janeiro, focusing on the organization and labor relations, the knowledge generated in the work processes, and networks of collective action established with the community. The data was obtained through interviews with the workers and their leaders and with the technicians of the NGO Autre Terre, which supports the project. The results of the qualitative research suggest that this experience of solidary and popular economy has become an alternative for social inclusion, creating employment, income, knowledge, and values, in the perspective of a popular and critical education. In the relations of the cooperative with the community are established networks of collective action, recovering the public space in which the awareness of the diversity of ideas and concepts can make it possible to be a good citizen.

Keywords solidary economy; popular education; social movements; cooperativism. 


\section{Introdução}

A crise do trabalho que vem afetando os países periféricos nas últimas décadas surge como consequência de dois processos estruturais de evolução do capitalismo: o de modernização da produção e do mercado nos países centrais e o de configuração do Estado, com suas crises fiscais, acompanhadas da ausência de políticas públicas sociais (Razeto, 2001).

$\mathrm{Na}$ primeira vertente, as mudanças tecnológicas e a reestruturação dos mercados internacionais atingem, de forma especial, a América Latina. Acentua-se o esgotamento da absorção da força de trabalho e, concomitantemente, amplia-se o acesso à satisfação das necessidades e aspirações de determinados segmentos da população. Há um aumento de interesse na produção de bens e serviços que atendam a estas, principalmente dos setores que ainda possuem capacidade de consumir e aumentar o lucro do capital.

Entretanto, permanece existindo um significativo grupo de sujeitos 3 posto à margem dessas mudanças, permanecendo no reino de necessidades mais básicas, as de sobrevivência, carecendo de bens e serviços, inscritos na categoria de essenciais.

Na segunda vertente, temos a realidade de um Estado que não tem conseguido assegurar, de forma efetiva e permanente, recursos e serviços voltados para o interesse público, e cujas políticas sociais vêm sendo efetivadas, em grande medida, pelas ações do mercado, através da privatização dos serviços e da constituição de um setor público não-estatal, onde atuam várias organizações, entre elas as organizações não-governamentais (ONGs).

Tais processos de configuração do capitalismo provocam um dualismo estrutural na economia e na vida cotidiana dos sujeitos. De um lado, o conjunto da economia está organizado segundo a lógica do capital e de sua acumulação, e o sistema de interesses na sociedade é hegemonizado pelos interesses do capitalismo internacionalizado. De outro, o conjunto da economia é visto a partir da lógica do trabalho e de sua reprodução ampliada, confrontando essa hegemonia e afirmando a primazia dos interesses do conjunto dos trabalhadores e de suas múltiplas identidades e agrupamentos (Coraggio, 2003)

A economia do trabalho ou popular é resultado de experiências, atividades e iniciativas que, estando deslocadas dos dois sistemas formais de destinação de recursos - mercado e Estado -, precisam organizar e garantir caminhos de subsistir, garantindo a satisfação de suas necessidades econômicas.

Icaza e Tiriba (2003) compreendem a economia popular no sentido de garantia da satisfação das necessidades básicas - materiais e imateriais -, através da utilização da força de trabalho e dos recursos disponíveis dos setores populares nas suas atividades econômicas e práticas sociais. A econo- 
mia popular encontra-se ligada diretamente à reprodução ampliada da vida, transcendendo a obtenção de ganhos materiais.

Para Razeto (2001), a economia popular é um fenômeno generalizado encontrado em toda a América Latina, dentro do contexto das transformações que vêm sofrendo o mercado e as estruturas econômico-sociais. $\mathrm{O}$ autor distingue três níveis de estratégias adotadas: as estratégias de sobrevivência, constituídas por atividades de emergência e transitórias para a satisfação de necessidades básicas de sobrevivência fisiológica; as estratégias de subsistência, quando há satisfação das necessidades, mas não são assumidas como opção permanente; e as estratégias de vida, que ocorrem com a valorização de certos espaços das atividades que realizam - a liberdade, o companheirismo, a autogestão -, buscando o crescimento dos empreendimentos para além da subsistência.

A economia popular se expressa de diferentes maneiras, e uma delas é a economia solidária, na qual, segundo Razeto (2001), as formas de produzir, distribuir recursos e bens, consumir e se desenvolver ocorrem através de características próprias, consideradas como alternativas ao modo capitalista hegemônico. Trata-se de uma racionalidade especial, em que o modo de constituir a economia implica mudanças comportamentais, sociais e pessoais na organização da produção e das empresas, na destinação de recursos e distribuição de bens e serviços produzidos, assim como nas formas de consumo e acumulação.

$\mathrm{O}$ autor destaca as características desse modo peculiar de ser: iniciativas que se desenvolvem nos setores populares; iniciativas associativas de pequenos grupos de pessoas ou familiares; experiências que dão lugar às organizações e aos empreendimentos; ações encaminhadas para enfrentar um conjunto de carências e necessidades concretas; iniciativas participativas, democráticas, autogestionárias e autônomas; iniciativas que tendem a ser integrais, articulando as dimensões econômica, social, educativa, pessoal, grupal e solidária, buscando satisfazer amplamente às necessidades e aspirações humanas; experiências que tendem a se coordenar com outras, com a formação de redes horizontais baseadas na troca de informações e nas ações conjuntas, associando necessidades e construção social.

Singer (2003) conceitua esta economia solidária como a organização de produtores, consumidores e poupadores, que se distinguem por duas especificidades: estimulam a solidariedade entre os membros mediante a prática da autogestão e praticam a solidariedade para com a população trabalhadora em geral, com ênfase nos mais desfavorecidos, sendo a cooperativa uma das formas clássicas desta espécie de empreendimento.

É no contexto da década de 1990 que se observa a ampliação de experiências de economia popular e solidária na América Latina e no Brasil, mas é importante ressaltar que, embora a maioria dos empreendimentos tenha 
surgido ou ganhado impulso na conjuntura dos anos 90, há experiências mais antigas que apontam para uma diversidade de demandas e de interesses, temporais e espaciais (Gaiger, 2004).

O solidarismo econômico entre os trabalhadores vem de longa data e materializase num conjunto heterogêneo de experiências de diferentes proveniências, em época e lugar, a formar uma história por fios que se entrelaçam em determinados momentos, história da qual a ecosol4 é por assim dizer mais um episódio, com um notável poder de revitalização dos ideais emancipatórios, de politização e de convergência das suas diversas expressões concretas (Gaiger, 2004, p. 3).

Neste período, ocorre também um redirecionamento dos propósitos da educação popular. Esta, que tinha seus objetivos mais centrados na política e na transformação da sociedade, sofre um redirecionamento para as questões do indivíduo, sua cultura e suas representações (Gohn, 2002). Assim, apesar das atividades de educação popular historicamente terem privilegiado os processos de alfabetização de adultos e de promoção de desenvolvimento local, posteriormente orientaram-se para "intervenções no terreno da consciência, da ideologia e da cultura" (Coraggio, 2000, p. 127). Para o autor, a educação popular possui enfoque educativo, voltado aos grupos à margem do sistema formal de ensino e um direcionamento para além do campo educativo, abrangendo o campo político, que considera a exclusão e os oprimidos do sistema social.

Esta perspectiva no interior dos novos movimentos sociais surge desde os anos 70, com a mudança paradigmática que envolve as ações coletivas dos movimentos populares, que atuam

no interior de um campo ético-político, campo esse que supõe (...) a existência de uma sociabilidade comum aflorada pelo senso de pertença a um mesmo espaço compartilhado de relações interpessoais e atributos culturais, como signos de linguagem, códigos de identificação, crenças religiosas e assim por diante (Doimo, 1994, p. 68).

Para a autora, estes "jamais reproduzirão o padrão clássico do conflito de classes porque as contradições agora são de outra ordem e porque os conflitos aí instalados são metapolíticos, ou seja, muito mais pautados em valores do que em reivindicações negociáveis" (Doimo, 1994, p. 46). Nesse sentido, as formas de ação tenderiam mais à autonomia em relação ao Estado do que à exigência de que este primasse por uma pauta política coletiva.

Assim, Doimo (1994) destaca uma dicotomia no que tange ao entendimento das ações coletivas acerca do campo ético-político dos movimentos populares: ora expressivo-disruptiva, envolvendo valores éticos morais e 
apelos éticos políticos conformando barreiras intergrupos, ora intergrativamente-corporativa, envolvendo maior nível de integração social através da acessibilidade a bens e serviços, porém, considerando os conflitos e as disputas imanentes aos próprios grupos e às forças oponentes a esse movimento.

Na perspectiva da educação popular, Gohn (2006, p. 28) apresenta o conceito de educação crítica não formal como "aquela que se aprende 'no mundo da vida', via os processos de compartilhamento de experiências, principalmente em espaços e ações coletivas cotidianas". Seus resultados esperados são a conscientização e a emancipação dos indivíduos e grupos e a construção de conhecimento sobre o mundo e as relações sociais que os circundam. A educação crítica não formal prepara os indivíduos para a vida e suas adversidades, dando-lhes condições de desenvolverem sentimentos de autovalorização, de rejeição dos preconceitos que lhes são dirigidos e de luta para serem reconhecidos como iguais, dentro de suas diferenças (raciais, étnicas, religiosas, culturais, entre outras).

Neste sentido, Gutiérrez (2001, p. 100) sinaliza que "a produção e a organização são hoje, na América Latina, os componentes substantivos e sustentadores de todo o processo de educação popular". O autor destaca uma educação socialmente produtiva, onde a produção, a organização e a educação compõem um processo integrador e relacional. Existe uma relação sociopolítica que amplia o entendimento dos fatores econômicos, organizacionais e educativos gerados nas economias populares.

É possível, portanto, que no contexto da produção cooperativa e solidária a educação popular encontre novos caminhos e alternativas de ação, onde o trabalho socialmente produtivo também seja educativo. A solidariedade passa a ser enfocada tanto nos processos de economia popular quanto nos de organização e de educação popular.

Trata-se de ampliar os espaços educativos que promovam novos saberes e novas práticas sociais e, para isso, um dos pontos de partida é não só compreender a produção associada como instância educativa, mas captar as formas como os trabalhadores de atividades populares vêm organizando seus empreendimentos para além da reprodução ampliada do capital, no sentido da reprodução ampliada da vida, como sinalizou Coraggio (2000).

Tiriba (2001, p. 210) aponta a produção associada como lugar onde o mundo do trabalho "é princípio e fim educativo, é fonte de produção de conhecimento e de novas práticas sociais, é fonte de produção de bens materiais e espirituais". Lembra-nos de que não se trata da mera substituição do espaço educativo escolar, mas da necessidade de ampliação do conhecimento dos trabalhadores sobre o mundo do trabalho, ressaltando ainda o risco de que os objetivos que norteiam os processos educativos de formação dos trabalhadores se voltem apenas para a lógica da empregabilidade e da sobrevivência. Gutiérrez (2001, p. 25) aponta que os interesses externos aos 
setores populares podem imputar a esse processo de formação uma lógica instrumental ao "manter a atual estrutura produtiva com uma roupagem modernizante, desconhecendo os objetivos e a natureza sociopolítica de todo o processo de desenvolvimento humano".

Nasciutti (2001), ao relatar algumas experiências com projetos de ação comunitária (oficinas, rádios comunitárias, reciclagens de lixo, oficinas profissionalizantes, creches, centros de lazer, música, artes, entre outras), ressalta que por mais distantes que estas possam parecer estar das ações econômicas, culturais, ambientais que primem pela integralidade do ser humano em sua relação social mais global, o que se pode apreender são elementos ricos em aspectos da cidadania, resgate de auto-estima, conscientização e construção de sujeitos políticos, a partir da superação da passividade e da ação coletiva organizada.

É neste contexto que se situa a Cooperativa de Reciclagem de Lixo (Coopcarmo), localizada no município de Mesquita, Baixada Fluminense, no Rio de Janeiro, que é formada por 19 cooperados, pessoas situadas na linha de pobreza e abaixo dela 5 - em sua maioria mulheres -, e tem como filosofia a geração de trabalho e renda, a inclusão social e o resgate de cidadania através da ação de coleta seletiva na comunidade local e nos municípios adjacentes. Atualmente, a cooperativa vem estabelecendo parcerias com o poder público - prefeitura do município de Mesquita -, com empresas como a Petrobrás, com o fim de implementar projetos de coleta seletiva e bene-ficiamento do lixo, formação e inserção de catadores de rua em atividades socioambientais, bem como com escolas municipais, comércio e comunidade local.

Observamos que, apesar de serem sujeitos imersos na exclusão social, ${ }^{6}$ alguns puderam iniciar a percepção de si a partir do trabalho cooperativo que emergiu do projeto inicial, Lixo é Vida, com o apoio da ONG Autre Terre $^{7}$ (Ernest, 2005). O projeto vem se constituindo em um espaço de resistência e de reinvenção, ampliando e redimensionando os conhecimentos ali gerados, construídos a partir do trabalho coletivo cooperativado e das ações educativas não formais estabelecidas sob a forma de uma nova economia, a que Singer (1997) chamou de única alternativa válida e progressista ao capitalismo.

Este estudo 8 é resultante das inquietações geradas por esta experiência e direcionou-se a partir da perspectiva expressa por Martins (2000, p. 135): “Há nisso uma proposta metodológica e teórica: observar a sociedade a partir da margem, do mundo cinzento daqueles aos quais as contradições da vida social deram a aparência de insignificantes e que como insignificantes são tratados pela ciência. E, no entanto, se movem."

O objetivo foi analisar as experiências e práticas desenvolvidas pela Coopcarmo, enfocando a organização e as relações de trabalho, os saberes 
produzidos nos processos de trabalho na cooperativa e as redes de ação coletiva que são estabelecidas com a comunidade, a partir das atividades socioambientais. O estudo orientou-se pelos pressupostos da pesquisa qualitativa em educação, ancorando-se em uma ótica compreensiva e dialógica, que levou em conta o contexto histórico, econômico, sociopolítico e cultural, e enfatizou os significados e as perspectivas dos sujeitos, inseridos em seu contexto. Envolveu a imersão do pesquisador na realidade social e considerou o ambiente natural como fonte direta de dados, no qual os sujeitos - elementos participantes do estudo - interagem. Teve como proposta metodológica um plano de pesquisa participativo, objetivando-se na prática e na interação cotidiana dos sujeitos.

O trabalho de campo ocorreu no período que compreendeu o último semestre de 2003 a fevereiro de 2005 e desenvolveu-se dentro da cooperativa e a partir da observação-interlocução com seu entorno, estando esta situada no bairro de Jacutinga, município de Mesquita.

Através de um roteiro 9 adaptado dos estudos de Tiriba (2001), foram realizadas entrevistas semiestruturadas com a liderança da cooperativa, com a representante da ONG Autre Terre e com a facilitadora do grupo contratada pela ONG, utilizando-se o recurso do gravador. Foram registrados, igualmente, relatos livres de 12 dos 19 cooperados, sob forma espontânea de participação, com suas histórias de vida. Foi, ainda, realizado um processo de acompanhamento e observação do projeto piloto Jovem e Meio Ambiente, através de reuniões, ensaios, apresentação/culminância, onde se utilizou a técnica da observação com diário de campo, e registro das falas, posteriormente transcritas.

Além dessa etapa, foram estabelecidos diálogos constantes com a produção documental, através da pesquisa bibliográfica acadêmica e da análise documental dos materiais produzidos pela cooperativa, tais como estatuto e regimento interno, atas de reuniões, registros, folders, banners, fotos e projetos, realizados no decorrer dos 12 anos de existência do projeto Lixo é Vida, e dos materiais oriundos da ONG Autre Terre, através de site da internet, 10 publicações, projetos e outros, possibilitando uma construção que articulou teoria e prática.

A partir das entrevistas semiestruturadas, das observações e da análise documental, buscou-se compreender a organização, as relações de trabalho e os saberes construídos na prática do trabalho da cooperativa; analisar a cooperação como forma de organização do trabalho e como aprendizado; constatar quanto se ganha e quais as condições de trabalho; e observar como se aprende e se produz conhecimento na cooperativa e como se estabelecem as redes de ação coletiva e os espaços de aprendizagem, tendo como objetivo final compreender as percepções do grupo de cooperados sobre o trabalho, a educação e o meio ambiente e as concepções e intenções da ONG Autre Terre em relação ao projeto Lixo é Vida e a cooperativa. 
Partimos do pressuposto de que a relação entre educação e trabalho não pode continuar a ser vista unicamente sob a ótica da produção e do consumo, onde há ênfase nas competências e habilidades para uma educação basicamente voltada para os processos produtivos, mas deve ser necessariamente transpassada por uma dimensão sociopolítica (Deluiz, 1995), com prioridade nas experiências de solidariedade e de realização pessoal e coletiva no âmbito de um projeto social mais democrático. Santos (1997) referese às perguntas que fazem avançar o conhecimento, denominando-as como aquelas capazes de penetrar nos pressupostos epistemológicos e ontológicos do saber constituído, onde o valor e a ética são introduzidos nos conceitos científicos, chamando-as de perguntas poderosas e contra-hegemônicas. Esta perspectiva é reiterada por Bourdieu (1998), ao dizer que é necessário lutar contra a tecnocracia econômica, através do emergir do conhecimento dos homens, do seu cotidiano e do seu sofrimento.

Buscamos refletir sobre essa realidade a partir da investigação dos processos educativos populares não formais e de busca de formas alternativas de inserção social destes trabalhadores no mundo do trabalho. Foi partindo de um olhar local - um estudo de caso -, que o implicamos em uma ótica global, propondo-nos um resgate dessa realidade como organização e resistência social, compreendendo o contexto sociohistórico daquela comunidade em seu diálogo com o macrocontexto social.

\section{A Coopcarmo: organização e relações de trabalho e saberes construídos na prática do trabalho}

Os resultados de pesquisa qualitativa realizada na Coopcarmo com cooperados, liderança da cooperativa e técnicos da ONG Autre Terre indicam que, ao se referirem ao trabalho que realizam na cooperativa, os trabalhadores o apontam como atividade vital e destacam sua importância e seu significado em suas vidas:

Para mim é muito claro. É uma questão de dignidade. Você passa a se sentir como as outras pessoas. Para mim, ele (o trabalho) construiu muita coisa: vida, esperança, dignidade, vontade de viver (sic) (Cooperada 1).

Para mim é tudo. É o meu meio de sobrevivência. É onde eu tive oportunidade de aprender que eu sou um ser humano. Da onde a gente não espera é que surge vida. Em relação ao projeto, eu pretendo que mais pessoas estejam aqui produzindo. Ver isso aqui crescendo (sic) (Cooperada 2).

A despeito da discussão teórica que enfatiza a perda de centralidade da categoria 'trabalho para o entendimento da atividade humana e para a 
determinação da estrutura e do desenvolvimento da sociedade contemporânea' (Offe, 1989), o trabalho é considerado elemento norteador dos projetos realizados pela ONG Autre Terre, que apoia o projeto Lixo é Vida, como observado na fala da representante belga no Brasil:

(...) A Autre Terre, uma ONG que foi formada em 1971, tem como missão apoiar parceiros no sul do planeta e com essa ideia sempre de geração e renda e trabalho. Não por desprezar as atividades de cultura, educação, saúde, mas porque o grupo Autre Terre acha que a transformação e o resgate da vida passam pelo trabalho (sic) (Técnica belga, grifos nossos).

Na prática, os cooperados sabem da centralidade do trabalho em suas vidas e, ao vivenciarem suas experiências, vão também se inscrevendo historicamente na sociedade, constituindo sua identidade como trabalhadores, em oposição a outros segmentos sociais:

(...) Não é porque eu sou rica não, mas um dia eu fui pegar o lixo e vi muitas pessoas pedindo e fiquei pensando que poderiam estar procurando seu próprio sustento num trabalho. Mas elas estão ali mexendo no lixo que as pessoas jogam fora (...). É melhor você trabalhar e mostrar que é um ser humano. Às vezes as pessoas, por preguiça, preferem continuar pedindo. Eu digo isso porque quase cheguei a este ponto (sic) (Cooperada 2).

Na visão da liderança, um dos motivos da precarização dos catadores é a ausência de consciência sobre o próprio trabalho e sobre sua identidade como trabalhadores, o que os fazem perder a auto-estima e tornar-se dependentes da bebida alcoólica.

(...) Os catadores bebem demais (...), mas porque não têm nenhuma informação. Eu tenho orgulho de falar que trabalho com lixo. Agora, trabalhar com lixo, na cabeça de muitas pessoas, é um desprezo, né? Você chegou num nível da sua vida que não sabe o que fazer, não tem mais nada para você ter e fazer. Então, o álcool é uma maneira de você se esconder daquilo que faz. Ele leva as garrafas pet e aquele dinheiro é tão pouco (...). Porque o catador, na verdade, é o desempregado que não consegue mais trabalho e ele tem que sobreviver de qualquer maneira (sic) (Liderança cooperada, grifos nossos).

Partindo das dificuldades concretas do mundo do trabalho e do cotidiano de sobrevivência, os trabalhadores cooperados identificam em suas histórias pessoais a trajetória do trabalho 'formal' precarizado e reconhecem a ausência de qualificação e de espaço nesse mercado de trabalho. Neste momento, outras formas e possibilidades de trabalho surgem como alternativas 
à realidade específica e comum daqueles sujeitos, dando início a uma ressignificação do mundo do trabalho que passa a traduzir-se pelas ações dos trabalhadores no sentido de um trabalho cooperado, que guarda outros valores para além da produção e do lucro.

(...) Geralmente o problema das pessoas é este mesmo, porque o trabalho tem que ser aquele trabalho convencional, de carteira assinada, que você vai ali todo dia e muitas vezes tem tempo de trabalho determinado. Você vai ali só para ganhar aquele dinheirinho e pronto. A própria empresa te proporciona isso, você não quer nem saber. Ir já pensando no ganho do final do mês. Aqui já é totalmente diferente. Quando você trabalha numa empresa de carteira assinada, a sua preocupação é: quanto será que eu vou ganhar este mês, será que vai dar para pagar minhas contas, vai dar para comprar minha comida? Agora a nossa preocupação mudou. É será que o que eu vou ganhar vai dar para pagar minhas contas, para comprar minha comida, para pagar as taxas da minha cooperativa, para pagar as contas que a cooperativa tem? (sic) (Liderança cooperada).

Entretanto, o trabalho cooperado encontra-se imerso na seguinte contradição: o desafio de enfrentar o mercado competitivo e, ao mesmo tempo, manter a lógica do apoio cooperativo, formado a partir da ação coletiva, como relata a representante da ONG:

(...) a Autre Terre quer também apoia uma dinâmica de colaboração entre as cooperativas que trabalham no mesmo ramo, porque a 'salvação' e a 'verdadeira libertação' das pessoas dentro das cooperativas ocorrem quando elas começam se juntar para poder negociar melhor os preços, para poder tratar, beneficiar materiais. É a ação coletiva entre cooperativas (sic) (Técnica belga, grifos nossos).

\section{A cooperação como forma de organização do trabalho e como aprendizado}

O espaço de trabalho cooperativo na Coopcarmo possui características próprias, pois a ideia de vida coletiva, apesar de contextualizada dentro do ideário do capitalismo, não se justifica apenas para a acumulação numa perspectiva de produção e consumo: “(...) geralmente, as cooperativas só têm nome de cooperativa e pronto. Mas é a forma de trabalhar (...). Aqui a gente tenta fazer diferente. Dá um trabalho maior, né?" (sic) (Liderança cooperada).

Ainda que a organização do trabalho voltada para a cooperação seja vista como proposta alternativa de geração de trabalho e renda no atual contexto econômico, Cattani (2003) aponta como um dos desafios a ser enfrentado a demarcação precisa entre as verdadeiras alternativas e as práticas conservadoras do terceiro setor, que pretendem assegurar a hegemonia 
das elites dominantes na condução dos processos sociais, pelo risco de convulsão social ou do direcionamento da violência contra os poderosos. Nesta perspectiva, Fals Borda (1999 apud Nasciutti, 2001) alerta que, embora as cooperativas populares venham exercendo uma ponte entre as práticas comunitárias e as demais organizações sociais de ordem mais complexa, aquelas acabam recebendo apoio político tendo em vista seu papel no apaziguamento das demandas sociais e na reprodução/manutenção da estrutura da comunidade, através do controle por grupos majoritários e/ou da cooptação das lideranças.

Entretanto, Razeto (2001) lembra-nos da importante contribuição dos projetos ligados ao associativismo, ao cooperativismo e à economia popular, cujo cerne de ação é o resgate dos sujeitos e de suas relações cooperadas e solidárias para além da lógica meramente capitalista.

Na Coopcarmo, a organização do trabalho baseia-se na divisão de tarefas visando à produção, atuando a favor da preservação ambiental, no caso a coleta e a reciclagem do lixo, buscando transformá-lo em mercadoria. Entretanto, há todo um processo de aprendizagem próprio do cooperativismo, como o trabalho em equipe, onde os valores coletivos sobrepõem-se aos individuais, como relata uma técnica brasileira contratada pela ONG, ao se referir ao cotidiano de trabalho na cooperativa:

(...) A gente aprende aqui dentro fazendo. Aprende a repensar muitas coisas e muitos valores, porque parece um formigueiro organizado, tem um ritual, tem um movimento, que é próprio deles, ao mesmo tempo os corpos somem e aparecem, mas ao mesmo tempo é uma mágica, um movimento próprio que vem e faz. Chegam do caminhão cheio de materiais e equipamentos... Eles se reciclam, e eu acho que eles são muito abertos também e falam as coisas (sic) (Técnica brasileira, grifos nossos).

Este processo de organização da cooperativa e de compreensão da sua concepção pelos cooperados ocorre durante as reuniões do grupo, mas a construção do cooperativismo não é fácil, uma vez que há exigências que têm de ser cumpridas:

(...) então você muda, passa de empregado a patrão e aquelas preocupações que você tinha só de empregado passa a ter de empregado e de patrão, né? Hoje, essa é a minha preocupação. Então o trabalho para mim é diferente. Hoje eu trabalho numa coisa que eu ajudei a construir e eu acredito nesse trabalho (sic) (Liderança cooperada).

Nasciutti (2001) aponta que a proposta inicial das cooperativas de constituírem-se como uma alternativa ao modelo capitalista passa a ser pressionada 
pelas necessidades de agilidade e articulações demandadas pelo mercado, e o espaço de decisão coletiva - próprio do cooperativismo -, fica ameaçado devido às exigências de 'modernização administrativa' e de 'lideranças' com perfil empresarial.

(...) Dentro do cooperativismo tem que ter a assembleia geral, a ordinária e a extraordinária, além das reuniões de diretoria e as reuniões da equipe que trabalha com o conselho fiscal, e aqui na cooperativa ainda não tem. A gente não conseguiu fazer ainda porque a gente não fez balancete. Vamos fazer esse ano o primeiro balancete (sic) (Liderança cooperada).

As considerações da liderança envolvem a necessidade da existência da comunidade como espaço de discussão, planejamento e escolhas, no qual as ações coletivas e cotidianas norteariam o processo de consolidação do trabalho cooperado, na perspectiva de uma ação popular solidária e de uma educação popular crítica.

Contudo, estas ações são marcadas pelos fazeres inerentes à reprodução da existência. Razeto (2001) destaca a heterogeneidade e a diferenciação interna desse tipo de organização econômica, caracterizada por ele como Organizações Econômicas Populares (OEPs), grupos que no coletivo estariam buscando formas de enfrentamento de problemas econômicos, sociais e culturais mais imediatos.

É identificado na forma de organização da Coopcarmo um tipo mais específico de economia popular, a economia solidária cooperativada, onde as formas de produzir, distribuir recursos e bens e consumir possuem características próprias, diferenciadas do modo capitalista dominante:

(...) a gente não trabalha dentro dessa forma do capitalismo, né? A gente bate de frente, de repente será que é isso que faz a gente vencer cada vez mais? A essência do trabalho que a gente fala, a filosofia do grupo, né? Porque é aquilo que eu falei dos trabalhos convencionais, até na hora de selecionar a pessoa que vai trabalhar precisa pensar muito, né? (sic) (Liderança cooperada).

A liderança e alguns cooperados passam a assumir as responsabilidades inerentes a uma produção diferenciada, onde o 'fator $\mathrm{C}^{\prime}$ - traduzido pela cooperação, colaboração, coordenação, comunidade e coletividade prevalece sobre o 'K' (capital) e o 'L' (labor/trabalho) (Razeto, 2001):

(...) Dentro do cooperativismo nem do horário você pode falar, porque o cooperado não tem hora para chegar na cooperativa, mas só que aqui é uma cooperativa totalmente diferente, que tem um compromisso. Porque geralmente as cooperativas que trabalham com lixo, eles são catadores. O catador fica a hora que ele quer, 
trabalha o dia que ele quer. E aqui não, entendeu? Aqui tem aquele compromisso com os entrepostos. Tem que ir lá no dia certo coletar (sic) (Liderança cooperada).

\section{Quanto se ganha e quais as condições de trabalho?}

O início dessa organização foi marcado apenas pelo investimento que cada sujeito fez, tomando aquele trabalho como uma possibilidade. Parafraseando Razeto (2001), o capital a ser investido foi o trabalho que, nesse caso, está permeado pela cooperação:

(...) Naquela época era muito pouquinho, tinha que ter que esperar quatro meses para receber trinta reais. É uma questão de sobrevivência. Mas a gente, no princípio, já trabalhou por bem pouco (Cooperada 1).

Cristina, cooperada, lembra que quando apresentam o trabalho nas escolas e nos demais espaços aparece a preocupação das pessoas em saber como se dá a remuneração das atividades da cooperativa - como e quanto ganham:

(...) Eles perguntam se a gente ganha salário. Tem carteira assinada? Não, trabalhamos com nossa partilha. É assim a partilha: nós juntamos o material, separamos e vendemos. Aquele dinheiro é junto. Somos 19 'funcionários', aí o valor que der a gente divide pelo número de 'funcionários'. Como distribuímos o material? Tudo o que a gente faz a gente passa [referindo-se ao processo de ensinar o serviço]. Tentamos tirar todas as dúvidas deles (Cooperada 3).

O mercado informal encontra-se à margem da economia, mas não fora dela, como nos lembra Martins (2000). Nesse sentido, a liderança explica como realmente é feita a divisão dos valores apurados e qual é a jornada de trabalho, tal como constam do regimento interno e do estatuto da Coopcarmo:

(...) Um salário mínimo tem sido a média, trabalhando das 7 às 17 horas. Isso é porque são $20 \%$ para taxa de administração em cima do bruto de cada um e depois se desconta $\mathrm{R} \$ 15$, que é a taxa de manutenção para as despesas gerais. Fazemos uma divisão: primeiro a gente vê os dias trabalhados pelo bruto. Aí divide os dias trabalhados pelo bruto que vai dar o ganho por dia e este ganho por dia é multiplicado pelo número de dias trabalhados. E tem o descanso semanal, sábado e domingo. Só se tiver necessidade mesmo é que a gente trabalha aos sábados (sic) (Liderança cooperada).

Apesar de reconhecerem a importância e o desenvolvimento do trabalho em suas vidas, a precarização do trabalho é destacada pelos cooperados 
como algo a ser superado, referindo-se às condições de realização do mesmo dentro e fora da cooperativa:

(...) Na fábrica, a gente trabalhava sentado. Era tudo limpinho. Aqui não. A gente fica com muita dor na perna. Também, trabalhando abaixado e no sol, né? (sic) (Cooperada 4).

(...) A diferença é que eles não trabalham no sol [referindo-se aos trabalhadores formais]. Trabalhamos no sol e tem vezes que acham que gente não está trabalhando (sic) (Cooperada 5).

A necessidade de segurança e garantia no trabalho é alvo da preocupação dos cooperados. Após a constituição da cooperativa, passaram a fazer a contribuição para a previdência, não antes de muitas discussões sobre como viabilizar essa questão:

(...) Garantia, né? Porque, como se diz, de uma hora para outra a gente adoece e não tem como trabalhar mais. Com todos nós pode acontecer. Aí, a gente tendo o INSS, tem uma garantia. E se a gente não tiver? Como é que fica? O que vai acontecer? Vai ficar em cima da cama. Eu não apoio tudo. Eu ajo com o que eu entendo que é certo. Sem dinheiro para comprar remédio? Aí eles falam: "Você apoia tudo." Não, mas eu vejo como segurança (sic) (Cooperada 1).

Você pode estar doente, mas pode estar ganhando, né? Então é por isso que o grupo agora paga o INSS, para essas eventualidades. Ficou doente (...), ganhou neném, pode ficar em casa que vai receber auxílio-maternidade. Sofreu acidente, até mesmo no trabalho, tem remuneração (sic) (Liderança cooperada).

Diferente de outras formas de produzir, a Coopcarmo mantém sua produção a partir do lixo social. Este tem tido seu crescimento dado aos diversos fenômenos promovidos pelo processo de globalização, entre eles, a geração de consumo marcada pela descartabilidade. Buarque (2001, p. 207) aponta que tal 'produção' é fruto da modernidade: consumidores produzem excesso de lixo, e a concentração de renda produz um excesso de pobreza: "as sociedades pobres não têm tanto lixo; as justas não têm tantos pobres".

Na problemática do lixo, encontra-se o fazer da Coopcarmo, que a partir dos 'excessos' vem buscando estabelecer um trabalho que incorpore produção, mas também trabalho educativo para o coletivo social:

(...) eu acho que é por isso também que eu tenho outra visão do trabalho. Porque eu sei a importância que o meu trabalho tem. Porque eu não sou simplesmente uma catadora de lixo, né? Eu sou uma ecologista? Uma empresária? Trabalhadora? 
Eu sou tudo isso. Vivo muito isso: a importância desse trabalho. É muito importante o meu trabalho (sic) (Liderança cooperada).

A produção na Coopcarmo se dá pela coleta de lixo seletivo nos entrepostos (residências, empresas, escolas e outros), pelo transporte, despejo, separação, organização e catalogação, prensagem, pesagem e comercialização dos materiais às empresas, além do reaproveitamento artesanal com a criação de novos produtos, em especial objetos de uso e decoração, como é o caso das oficinas de cestaria e papel. A construção de conhecimentos sobre o que se produz pode ser vista nas falas:

(...) Ah, tem hora que eu fico pensando, como é que pode do lixo sair um monte de material que a gente pode trabalhar? Eu nunca vi esse tipo de trabalho assim. Eu vejo o caminhão do lixo pegando o lixo e agora fico imaginando que dá dinheiro, que nem o papelão. Muita gente aí sustenta a família assim, com a venda de papelão (sic) (Cooperada 8).

(...) Então a gente tem aí a pet que vai para várias coisas. Pet não vira pet de novo, como no caso das LAV [latinhas de alumínio vazias]. O pet pode ser reaproveitado: móvel, sofá, estante. Já o papelão é diverso. Papelão é reciclado (sic) (Liderança cooperada).

Os principais materiais coletados pela Coopcarmo são metal, plástico, papel e vidro, os quais se desdobram em inúmeras classificações e finalidades. Estas é que atendem ao interesse do mercado e isso foi uma árdua descoberta para os cooperados, pois não se tratava apenas de juntar material e vender, mas de decidir o que vender e a quem vender, buscando essa qualificação no seu próprio fazer:

(...) Tivemos que aprender a nos comunicar muito para poder achar os compradores certos. Hoje em dia a gente tem os compradores. Para cada mercadoria a gente tem o comprador certo. Um para o plástico, outro para o jornal (...) (sic) (Cooperada 1).

Provocando os cooperados para o aprendizado sobre os produtos com que lidam, a liderança estabelece uma dinâmica de identificação dos materiais:

(...) quem viu o polietileno de alta densidade, quer dizer onde está? E o polietileno de baixa densidade, cadê o papelão colorido, cadê o papelão ondulado? Aí no outro dia eu vou trabalhando e vou perguntado para eles, né? O plástico é derivado de quê? Quantas árvores deixam de ser derrubadas quando se recicla um papel? Coisas assim que é para ver se eles guardam. Como é o nome desse 
material aqui? Cadê a malha de alumínio? Às vezes eles ficam todos perdidos ( $s i c$ ) (Liderança cooperada).

\section{Como se aprende e se produz conhecimento na cooperativa?}

A escolaridade formal dos cooperados encontra-se em torno do Ensino Fundamental incompleto, a maioria sem o término do primeiro segmento.

(...) Eu queria aprender a escrever, porque sei ler a Bíblia, e soletro 'lixo é vida', recicle, lixo é vida, mas eu não consigo gravar as letras. É isso que acontece comigo (sic) (Cooperada 8).

Segundo a opinião da técnica da ONG, a superação das dificuldades em relação ao processo de conhecimento passa pelo resgate do sujeito integral, iniciando-se pela reconstrução de sua auto-estima, do reconhecer-se como alguém capaz de realizar:

(...) eu acho que educação é o grande caminho, educação para mim é convivência, conhecimento, experiência (...), então eu acho que começa por aí, você trabalhar a auto-estima, depois a autonomia (...). Vem o momento da palestra, a gente também tem os cinco minutos do 'fala grupo' na reunião, que é para eles se colocarem, fazerem os folhetos. São ações que a gente está tentando, além das oficinas (sic) (Técnica brasileira).

A formalidade e a não formalidade das ações educativas no trabalho tecem-se em conjunto. A organização e a dinamização das reuniões da cooperativa, o registro das discussões e decisões coletivas em atas, a organização dos roteiros de coleta seletiva nos entrepostos, a preparação das escalas de atividades - coleta no caminhão, separação na reciclagem, a organização do bazar de venda de peças reaproveitáveis -, mesclam-se à intuitiva preparação dos textos dos folders de divulgação, à organização/catalogação experimental de materiais recicláveis, às dificuldades geradas pela ausência de letramento, até ao fazer-ação no momento de 'ensinar o serviço' a outro cooperado.

Esses saberes têm sido trabalhados nos espaços não formais de ações do grupo como os relatados acima pela técnica da ONG, a exemplo do espaço do 'fala grupo', onde cada um pode trazer informações, falar das questões comuns ou individuais, num exercício de reconhecimento da realidade e das possibilidades de sua transformação, que Gutiérrez (2001) chama de uma ação educativa socialmente produtiva, onde elementos em conjunto constituem um processo integrador e relacional. 
Fica claro que as tentativas de escolarização se tornam distanciadas, uma vez que o universo da educação formal apresenta-se cindido da realidade dos cooperados, que, apesar de desejarem resgatar a questão da escolarização, encontram impedimentos, como aponta uma cooperada, ao se referir à possibilidade de voltar à sala de aula:

(...) Ah! Fica todo mundo olhando para a minha cara, todo mundo rindo. Ah, se ainda fosse aqui, ia ser mais fácil, mas eu acho que eu não vou conseguir aprender nada não, como quando eu tiver que gravar as coisas que nem as crianças. Já me falaram: "Por que você não arruma um serviço em uma loja?" Aí eu digo: “Gente, eu não vou conseguir trabalhar no mercado, fazer conta, eu não tive estudo, não sei matemática" (Cooperada 8).

Retomando Freire (1987), o que parece gerar tal distanciamento é que no trâmite educativo se insiste apenas em ler a palavra, esquecendo-se de que esta deveria se destinar a ler o mundo, sua cultura, seu sentido, pois:

Existir humanamente é pronunciar o mundo, é modificá-lo. O mundo pronunciado, por sua vez, se volta problematizado aos sujeitos pronunciantes, a exigir deles novo pronunciar. Não é no silêncio que os homens e mulheres se fazem, mas na palavra, no trabalho, na ação-reflexão (Freire, 1987, p. 92).

Nesse sentido, a educação popular assume o aporte e o suporte necessários ao entendimento das possíveis mudanças que são inerentes ao processo de educação pessoal e coletiva, como vemos no seguinte relato:

(...) Aqui o que vale é a força de vontade e a qualidade que nós temos aqui dentro. Nós temos vários conhecimentos. E para as pessoas que vão chegando a gente vai repassando conhecimento. Isso é educação pura! (sic) (Cooperada 2).

Esta fala nos remete ao que Gutiérrez (2001) destaca como os componentes substantivos e sustentadores da educação popular: a produção e a organização. Em uma educação socialmente produtiva, esses elementos em conjunto constituem um processo integrador e relacional.

Parece ser nesse processo de integração que acontece a produção e a socialização do conhecimento dentro da Coopcarmo e nas suas relações com a comunidade. Retomando Gutiérrez (2001), um grupo que, de forma associativa, trabalha e reflete de forma crítica e dialógica sobre as suas produções vive, certamente, um intenso processo educativo.

(...) O que a gente aprende aqui passa para os outros. Ainda não sei falar direito. Aprendi o que é pet, o que é um papel, plástico. Mas a gente já sabe que em uma 
palestra dá para falar alguma coisa. Eu nunca fui dar palestra. Acho que vou ficar com vergonha de falar (sic) (Cooperada 7).

A produção associada se estabelece como instância educativa (Tiriba, 2001), que educa os cooperados não só a partir das relações que se estabelecem nos fazeres cotidianos, mas nas demais relações com a sociedade. É interessante a fala desta cooperada ao se referir à dinâmica empregada ao ministrarem palestras sobre o trabalho da reciclagem, seja nas escolas públicas ou privadas, empresas, comunidades e até mesmo universidades. É uma relação de saber não impositivo, mas marcado pelas dinâmicas participativas, nascido a partir do interesse e desejo daqueles que querem aprender.

(...) As pessoas elogiam a gente depois da palestra. A gente pergunta primeiro o que elas querem saber. Porque se a gente ficar falando, fala coisas que elas não querem saber (...). Então a gente só responde o que elas querem saber (...). Tem colégio que a gente chega e as crianças são debochadas. Mas é assim mesmo. Pelo nível delas, elas não são nada humildes. Deixam a gente sem jeito, né? Elas falam coisas que não sabem (...). Na coleta de lixo, a gente vê que está ensinando a reaproveitar os materiais. Muitas coisas que as pessoas jogam foram pensando que não vale mais nada a gente mostra que têm utilidade, vê que dá para reaproveitar (sic) (Cooperada 1).

Como foi ressaltado por Tiriba (2001), a produção e a acumulação do conhecimento, em especial quando se trata de uma produção associada, se dá no desvelar dos vários saberes do processo produtivo, através da articulação e promoção do conhecimento entre os sujeitos, da construção de valores e de sua própria reconstrução, como relata a técnica brasileira, ao se referir às experiências vividas nas oficinas com os cooperados:

(...) Na reciclagem, eu trabalho muito com as oficinas de fazer caderno, brinquedo, objeto, transformar roupa. Enfim, reaproveitar essas coisas para uma transformação, que eu acho que é um processo que trabalha a auto-estima, é você transformar uma coisa sem uso, que seria descartada, e aquilo ter uma função, uma vida de novo, com a sua participação. É uma coisa que mexe por dentro. É uma reconstrução (Técnica brasileira).

A construção e reconstrução dos conhecimentos não se restringem ao plano da produção, pois cada sujeito trabalhador cria suas próprias representações sobre si, sobre o seu trabalho e sobre o mundo, o que Coraggio (2000) denominou de formas alternativas de sociabilidade. As consequências das experiências vividas pelos cooperados são apontadas pela liderança: 
(...) Tem trazido ensinamento, tem trazido uma nova perspectiva para cada cooperado, assim existem mudanças na vida dessas pessoas. Houve uma mudança na vida da Vânia. A Vânia é uma moradora de rua, era uma pessoa que não tinha endereço, que não tinha casa, não tinha documento, não tinha nada, né? Hoje, ela se chama Dona Vânia. Tem uma casa e os entregadores batem palma para chamar Dona Vânia. Houve uma melhora na vida desse grupo, né? Talvez passe até despercebido para eles mesmos. Como eles cresceram. Quantas pessoas têm documento, podem ir ao banco receber? Ser cidadão mesmo, de verdade? (sic) (Liderança cooperada).

\section{Estabelecendo as redes de ação coletiva e os espaços de aprendizagem}

Segundo a classificação do Compromisso Empresarial para a Reciclagem (Cempre), de 1996, as cooperativas e os centros de triagem estariam na fase dois do primeiro nível da cadeia de produção de recicláveis. ${ }^{11}$ Nesse sentido, a Coopcarmo é produtora de material que possui valor agregado e este produto é considerado uma 'mercadoria'. Desta forma, a problemática e a valorização do lixo não é de interesse apenas dos desqualificados para o mundo do trabalho, mas de toda uma rede social, o que torna a questão complexa e paradoxal.

Atualmente, as relações estabelecidas pela cooperativa com o mercado parecem ser claras para os cooperados, assim como os saberes implicados na forma de produzir, na venda e na rentabilidade dos produtos comercializados:

(...) Como foi explicado na reunião, a gente vai pagar INPS, e aí muita gente disse: "Vai pagar como?" Vai ter condições da gente tirar os R \$ 36 da seguinte forma: com uma caçamba dessa aqui a gente arruma o dinheiro para pagar. Se a gente ganha R\$ 200 hoje, quando entregarmos esse material prensado e preparado, é claro que ele vai sair mais caro. Hoje a gente vende um caminhão de pet a R\$ 0,15 o quilo, mas se ele for tratado vamos vender a $\mathrm{R} \$ 0,35$. A gente gasta mais com energia, então não dá para vender pelo mesmo preço. Então não é porque eu não sei ler corretamente que eu não esteja entendendo nada, não (sic) (Cooperada 1 ).

Novas relações são constituídas com compradores que revelam formas diferenciadas de negociação, apontando para uma parceria:

(...) Vendendo material, procurando estar sempre atento ao preço do material, buscando sempre um preço novo. A gente já adquiriu até um vínculo com os compradores. Eles também sabem do trabalho social que a gente faz aqui, da importância do trabalho. Se estamos precisando de alguma coisa eles também ajudam, entendeu? Se precisamos de dinheiro emprestado na hora de pagar as 
contas, emprestam o dinheiro para repor. Este vínculo com os compradores é bom em parte, mas tem hora que não é muito bom (sic) (Liderança cooperada).

A liderança se refere aqui à relação que se estabelece ancorada em outros valores, ficando difícil, num outro momento, simplesmente tratar comercialmente as vendas:

(...) não é muito bom porque tem hora que você fica até receosa de chegar ou pedir um aumento, entendeu? Mas eu procuro ser muito honesta com eles, né? Quando aparece alguém aqui querendo comprar um material, eu digo: “Olha, fulano, apareceu alguém aqui querendo comprar o material" (sic) (Liderança cooperada).

O serviço de coleta seletiva realizado pela cooperativa beneficia uma extensa rede social, incluindo o mercado, o poder público e a comunidade e, em menor escala, aos próprios cooperados, como nos relata a representante da ONG Autre Terre:

(...) É um projeto exemplar pela sua filosofia de libertação. Entretanto, é um projeto frágil que tem de ser fortalecido. A gente trabalha com processos e não com resultados ainda, e o impacto vai demorar ainda para aparecer. Como na Europa (a exemplo dos projetos de coleta seletiva com trabalhadores belgas), demorou vinte anos para um começo de conscientização (Técnica belga, grifos nossos).

Neste sentido, tanto para a ONG Autre Terre quanto para os cooperados “o processo de conscientização da população é fundamental para a continuidade do projeto da coleta seletiva, cumprindo sua responsabilidade social de mudar mentalidades e hábitos para construir uma sociedade melhor" (Coopcarmo, 2004, p. 1).

Nas experiências de organização/realização de encontros e reuniões com órgãos públicos (prefeituras); na preparação para as palestras realizadas nas escolas e na comunidade; nos contatos com outros pares (grupos de catadores, cooperativas similares e Recicloteca do Rio de Janeiro); nas reuniões regionais e nacionais; e no contato e negociação com os compradores de materiais (o mercado) é que se constroem novos saberes e conhecimentos.

As práticas cotidianas da cooperativa nas suas relações internas ou nas relações com a comunidade, tais como promoção de coleta seletiva sistemática e organizada no município e nas adjacências; promoção de conscientização comunitária sobre o trabalho ambiental-social-cultural-econômico do projeto de reciclagem; palestras e atividades ministradas pelos próprios membros do grupo; ocupação de espaço de busca de cidadania (encontros, congressos e feiras, cursos de formação que tratem dos temas de interesse do grupo, como meio ambiente, reciclagem, cidadania e sustentabilidade); 
e promoção da reflexão cotidiana de suas práticas em reuniões organizadas e gerenciadas pelo próprio grupo - busca de gestão democrática - tornam-se instrumentos de ampliação de seus conhecimentos e saberes.

A partir destas práticas, o grupo promove o suporte dos 19 partícipes, que são hoje capazes de gerir seu próprio sustento, numa perspectiva de autonomia, solidariedade, dignidade e de resistência à exclusão e implantando, com essas ações, a possibilidade de criação, de reinvenção e de alternativas.

As atividades realizadas na cooperativa e suas formas de interação social, construindo redes de ação coletiva, caracterizam-se por alguns objetivos específicos, tornando-se primordial para o grupo o que chamam de lema - Lixo é Vida -, onde "o lixo gera trabalho, trabalho gera renda, renda devolve a dignidade e a possibilidade de prover a própria vida e a própria história" (Liderança cooperada).

\section{Considerações finais}

A análise das experiências e relações no trabalho da Coopcarmo apontou a relevância dos processos associativos populares de geração de trabalho e renda como contraponto à crise do mundo do trabalho e à crise socioambiental, vislumbrando outras formas de pensar as relações entre trabalho, natureza e educação.

Parafraseando Martins (2000), aqueles que o corpo social tomou por insignificantes e que como insignificantes são tratados permanecem, entretanto, em movimento e, justamente por isso, mantêm-se por mérito próprio inseridos na composição do movimento social.

Com relação aos aspectos do trabalho organizado e produzido pela cooperativa, é possível aos cooperados, liderança e ONG Autre Terre, perceberem o sentido da construção de um novo conceito de trabalho - um trabalho ressignificado a partir da consideração de outros valores - e a importância destes para o empoderamento dos sujeitos.

Cooperados, liderança e ONG Autre Terre, ao mesmo tempo em que buscam primar pela cooperação, solidariedade e democracia, encontram-se pressionados pela necessidade de produtividade e pelas exigências do mercado. Os benefícios conquistados pelo grupo se revertem para o mesmo sob a forma de subsistência digna, de aprendizagens e parcerias, entretanto, benefícios maiores e mais diretos acabam por direcionarem-se à sociedade e ao próprio mercado: os serviços a eles prestados têm dimensões bastante amplas.

Se por um lado a contribuição ao social é clara, por outro o acesso a uma formação ampliada e à qualificação formal não é contemplado, uma vez que a escola apresenta-se distanciada da vida e da realidade daqueles 
trabalhadores. Nesse sentido, o processo educativo dos cooperados vem ocorrendo dentro do espaço da organização e da produção, tentando o caminho da aprendizagem pelas potencialidades do espaço não formal, na busca do resgate da autoestima dos trabalhadores.

Em se tratando das ações geradas a partir da realização do trabalho da cooperativa, estas parecem residir no patamar do espaço público: cooperados, comunidade, poder público, empresas estatais e privadas, escolas, cooperativas, organizações ambientais e demais instituições sociais nacionais e internacionais, entre elas a ONG Autre Terre, vêm formando uma rede de ação coletiva.

Esta rede foi criada e projetos concretos que implicam mudanças sociais podem ser considerados, tais como: a instituição do Programa de Coleta Seletiva no município de Mesquita, em parceira com a Petrobras, que buscará estabelecer políticas públicas sobre a questão dos impactos ambientais; o projeto da Coopcarmo, Coleta Solidária, que está ocorrendo como projeto piloto com 350 residências cadastradas pela prefeitura com a capacitação; a abertura de espaço para publicização das questões socioambientais, como a I Expo Reciclagem e outros, que contaram com a participação de escolas, empresários, academia, comunidade, ONGs, pequenos expositores; experiências sobre reciclagem; oficinas de reaproveitamento; e projeto de capacitação de noventa catadores de rua que serão incluídos nos programas sociais da prefeitura, buscando o resgate da cidadania desse sujeitos que terão sua formação iniciada pela própria Coopcarmo.

A análise dessas experiências e relações nos traz contribuições das mais variadas dimensões: social, econômica, educativa, ambiental. Entretanto, parece ser nos campos da política e da cultura, que acabam por envolver todas as demais ordens, que se destacam as constatações desse estudo: uma forma de cultura cunhada inicialmente pelo trabalho, um tipo de trabalho (re)significado, que surge como princípio e fim educativo no cotidiano daqueles sujeitos e que vai se ampliando para as demais relações sociais.

A complexidade que envolve tais fazeres nos coloca diante de uma gama de contribuições que são desenvolvidas nas atividades realizadas pelo grupo, seja pelo montante de lixo recolhido da natureza (prestação de serviço público); pelo resgate dos sujeitos através da geração de renda e da recuperação da dignidade; pelas aprendizagens dos cooperados e da comunidade, sob a ótica de outros valores sociais; pelas novas oportunidades criadas; pelas relações estabelecidas com o poder público e privado; pela interação estabelecida com a escola e pela inclusão através do reapoderamento do espaço social, entre tantas outras.

A Coopcarmo, com seu movimento local e pontual, acaba por congregar para a 'roda de discussão' os mais diversos atores sociais, representativos e significativos de nossa sociedade, mesmo que estes se apresentem com 
intenções muito distintas. E não seria esse o maior propósito? O de resgate do espaço público como fórum social? Sabemos que não é pela busca de unanimidade e pela homogeneização que a sociedade se tornará mais equânime, mas pela garantia de um espaço de explicitação/publicização da diversidade de ideias e concepções, das diferenças, que poderemos viabilizar, e quem sabe alcançar, a possibilidade de democracia, de cidadania, de inclusão social e de uma economia realmente solidária.

\section{Notas}

1 Professora-Assistente da Universidade Federal Rural do Rio de Janeiro (UFRRJ), Nova Iguaçu, Rio de janeiro, Brasil. Doutoranda em Psicossociologia de Comunidades e Ecologia Social pela Universidade Federal do Rio de Janeiro (UFRJ). <anamarques.ufrrj@gmail.com> Correspondência: Rua Capitão Chaves, 60, Centro, Nova Iguaçu, Rio de Janeiro, Brasil, CEP 26221-010.

2 Pesquisadora do Conselho Nacional de Desenvolvimento Científico e Tecnológico (CNPq) e professora do Programa de Pós-Graduação em Educação Profissional em Saúde da Escola Politécnica de Saúde Joaquim Venâncio da Fundação Oswaldo Cruz (EPSJV/ Fiocruz). Doutora em Educação pela Universidade Federal do Rio de Janeiro (UFRJ). <ndeluiz@uol.com.br>

3 Pelos critérios da Organização das Nações Unidos (ONU), que considera extremamente pobre ou indigente quem vive com menos de um dólar por dia, o Brasil já cumpriu a meta ao baixar para 4,2\% o número de pessoas nestas condições - o percentual era de $8,8 \%$ da população em 1990. Ainda assim, há 7,5 milhões de brasileiros vivendo na indigência. É como se o Brasil tivesse uma Suíça inteira na miséria. Já os pobres, aqueles em condições levemente melhores, caíram de 42,033 milhões de pessoas para 36,153 milhões, uma população igual à da Polônia. O Instituto de Estudos do Trabalho e Sociedade (Iets) também aponta a queda da pobreza, mas seus dados diferem dos da ONU e da Fundação Getúlio Vargas (FGV). Conforme o Iets, a pobreza caiu de 30,5\%, em 2005, para 26,9\%, em 2006. Para o instituto, o país tem 49,043 milhões de pobres - quase 13 milhões a mais do que os apontados pela FGV - e um número maior de indigentes, que chega a 10,3 milhões. A diferença se dá porque, para o Iets, é pobre a pessoa com renda per capita inferior a $\mathrm{R} \$ 266,15$ (jornal Gazeta do Povo, abr. 2008).

4 Denominação familiar entre os ativistas da economia solidária no Brasil.

${ }^{5}$ Referente aos indicativos da nota 3.

6 Caracterizados aqui como despossuídos de bens e de direitos sociais.

7 A ONG Autre Terre tem atuação internacional e seu objetivo é apoiar ações de tipo econômico visando a atingir as causas da miséria. Atua desde 2002 no projeto Lixo é Vida, que se tornou uma cooperativa em junho de 2003, além de outros projetos no Brasil. 
$8 \mathrm{O}$ referido artigo é fruto da dissertação de mestrado As relações de trabalho, meio ambiente e educação na Coopcarmo - projeto Lixo é Vida: por uma sustentabilidade democrática da inclusão, orientada pela professora Neise Deluiz, e não contou com apoio de financiamento.

9 Este roteiro de pesquisa foi adaptado a partir do Roteiro de Pesquisa de Tiriba (2001), quando a autora trabalhou com OEPs, em sua tese de doutorado. Ele sofreu vários momentos de ajustes, buscando adequá-lo às necessidades da pesquisa de campo.

$10 \mathrm{O}$ site encontra-se em www.autreterre.org. Foi necessário o recurso da tradução, uma vez que os documentos da ONG (página, relatórios e publicações) encontram-se todos em francês. Agradecemos carinhosamente a Marcelo Renou pelo valioso trabalho de tradução e também de revisão.

$11 \mathrm{Na}$ base do primeiro nível da cadeia se encontrariam os catadores autônomos e, num segundo momento desse nível, as cooperativas organizadas e os centros de triagem; no nível dois, pequenos e médios sucateiros; no nível três, grandes sucateiros; e no ápice nível quatro -, os recicladores (Cempre, 2005).

\section{Referências}

BOURDIEU, Pierre. Contrafogos: táticas para enfrentar a invasão neoliberal. Rio de Janeiro: Zahar, 1998.

BUARQUE, Cristovam. Admirável mundo atual. Dicionário pessoal dos horrores e esperanças do mundo globalizado. São Paulo: Geração Editorial, 2001.

CATTANI, Antonio David. A outra economia: os conceitos essenciais. In: CATTANI, Antonio David. (Org.) A outra economia. Porto Alegre: Veraz, 2003.

CEMPRE (Compromisso Empresarial para a Reciclagem). O sucateiro e a coleta seletiva. São Paulo: Cempre, 2005, 32 p. (Série Reciclagem \& Negócios - Mercado de Sucatas).

COOPCARMO. Informativo n. 03. Mesquita: 2004.

CORAGGIO, José Luís. Desarrollo humano, economia popular y educación. In: GADOTTI, Moacir (Org.). Perspectivas atuais da educação. Porto Alegre: Artes Médicas, 2000.
Economia do trabalho. In: CATTANI, Antonio David (Org.). A outra economia. Porto Alegre: Veraz, 2003.

DELUIZ, Neise. Formação do trabalhador: produtividade e cidadania. Rio de Janeiro: Shape, 1995.

DOIMO, Ana Maria. A vez e a voz do popular: movimentos sociais e participação política no Brasil pós-70. Rio de Janeiro: Relume-Dumará, 1994.

ERNEST, Raphael. Las actions nord-sud Autre-Terre: récuperátion et recyclage. Journal Terre, n. 109, p. 18, été 2005. Disponível em: <www.autreterre.org/Uploads/ Documents/TERRE\%20109\%20BD.pdf> Acesso em: 25 jun. 2005.

FREIRE, Paulo; SHOR, Ira. Medo e ousadia: o cotidiano do professor. Rio de Janeiro: Paz e Terra, 1987.

GAIGER, Luiz Inácio. Sentido e viabilidade das novas formas de produção não capitalis- 
tas: alguns resultados de pesquisa sobre a economia solidária no Brasil. ISTR - International Society For Third-Sector Research, Sixth International Conference, Toronto, Canada, July 2004.

GUTIÉRREZ, Francisco. Educação comunitária e desenvolvimento sócio-político. In: GADOTTI, Moacir; GUTIÉRREZ, Francisco (Orgs.). Educação comunitária e economia popular. São Paulo: Cortez, 2001.

GOHN, Maria da Gloria. Educação popular na América Latina no novo milênio: impactos do novo paradigma. v. 4. São Paulo: ETD, 2002.

Educação não-formal, participação da sociedade civil e estruturas colegiadas nas escolas. Ensaio: aval. pol. públ. Educ. Rio de Janeiro, v. 14, n. 50, p. 27-38, jan.mar. 2006.

ICAZA, Ana M. S.; TIRIBA, Lia. Economia popular. In: CATTANI, Antonio David (Org.). A outra economia. Porto Alegre: Veraz, 2003.

JORNAL GAZETA DO POVO. Pobreza. Disponível em: <www.orbis.org.br/noticias/ noticia_mostra.php?id=104 $>$. Acesso em: 10 jun. 2009.

MARTINS, José de Souza. A sociabilidade do homem simples. São Paulo: Hucitec, 2000.

NASCIUTTI, Jacyara C. Rochael. Participação comunitária para melhor qualidade de vida. Série Documenta, n. 11, ano VIII. Eicos/Cátedra da Unesco de Desenvolvimento Durável. Rio de Janeiro: UFRJ, 2001.
OFFE, Claus. Trabalho: categoria-chave da sociologia? Revista Brasileira de Ciências Sociais, v. 4, n. 10, p. 5-18, jun. 1989.

RAZETO, Luís. Economia de solidariedade e organização popular. In: GADOTTI, Moacir; GUTIERREZ, Francisco (Orgs.). Educação comunitária e economia popular. São Paulo: Cortez, 2001.

SANTOS, Ana Maria Marques. As relações de trabalho, meio ambiente e educação na Coopcarmo - Projeto Lixo é Vida: por uma sustentabilidade democrática da inclusão. 2005. 203 f. Dissertação (Mestrado em Educação), Faculdade de Educação, Universidade Estácio de Sá, Rio de Janeiro: Unesa, 2005.

SANTOS, Boaventura de Souza. A queda do Ângelus Novus: para além da equação moderna entre raízes e opções. São Paulo: Novos Estudos, Cebrap, 1997.

SINGER, Paul. Economia solidária. In: CATTANI, Antonio David (Org.). A outra economia. Porto Alegre: Veraz, 2003.

. Economia solidária: geração de renda e alternativa ao liberalismo. Proposta, n. 72, p. 6-13, mar.-maio 1997.

TIRIBA, Lia. Economia popular e a cultura do trabalho: pedagogia(s) da produção associada. Ijuí: Unijuí, 2001.

Recebido em 05/08/2008

Aprovado em 08/06/2009 